\title{
The use of green walls in sustainable urban context: with reference to Dubai, UAE
}

\author{
M. A. Haggag \\ UAE University, United Arab Emirates
}

\begin{abstract}
The impact of urban development on the natural environment generates unique challenges to architects and engineers seeking passive design strategies in hot and humid climates such as those in Dubai. They are collaborating to design new buildings that are energy efficient, environmentally friendly, and architecturally significant. Passive cooling design techniques, which are recognized mainly in the old Dubai, are energy efficient and can be considered as a good alternative to mechanical cooling systems. Green roofs and façades are passive techniques and add more benefits not only for reducing the energy demand of buildings, but also for providing environmental benefits, including visual relief, accessible green space, and improving air quality. In recent years, greening systems have been practised in many hot cities, including greening directly on to roofs and walls, greening the cavity between walls, and incorporating greening systems within the construction of the wall. Green roofs are frequently used in cities like Dubai; however, practising green wall technology is still new despite its great benefits.

Based on the climatic condition of Dubai, this paper attempts to reduce energy consumption in buildings by adopting passive cooling strategies in the sustainable urban context of Dubai. The growing interest in incorporating vegetated green walls into sustainable building is highlighted. To achieve the aim of the study, the following objectives have been covered: to investigate the use of passive cooling strategies in Dubai; to enhance the energy performance by reducing the cooling loads and therefore identifying the optimal parameters for building skins; and to draw guidelines for architects, planners and developers to demonstrate the potential benefits of green wall technology. In this context various issues, including the urban development of Dubai, sustainability, passive cooling techniques, and the performance of green walls, are to be considered.
\end{abstract}

Keywords: Dubai, energy efficiency, green walls, passive design, sustainability. 


\section{Introduction}

Recent ongoing developments in Dubai have consequences on the urban environment. Minimizing the negative impact of the construction boom on the natural environment and the trend to improve the ecological performance of buildings are the main concerns of the sustainable practices in the city. These ideologies have been acknowledged by architectural firms designing and constructing sustainable projects that are energy efficient. Architects and developers, such as Creative Kingdom and Mirage Mille, have incorporated ecological and sustainable approaches in their designs. Various concepts and techniques have been used to develop energy-efficient buildings and cooling load avoidance. The use of natural ventilation, thermal mass, shading devices, vegetation, landscaping, and the double skin façades have been adopted. In recent years, green roofs and façades have been rarely practised despite their wide range of positive effects for buildings, inhabitants, and the environment.

The study shows the environmental benefits achieved by adopting passive cooling strategies and integrating green walls in sustainable urban contents. The paper argues the value of integrating green wall technology into the double skin façades.

\section{Urban development in Dubai}

Dubai, the second largest of the seven emirates of the United Arab Emirates (UAE) after Abu Dhabi, has become one of the most modern cities in the world. The city started its urbanization process in the late 18th century with a small fishing and trading village in the Arabian Gulf. Nowadays, Dubai has the largest population in the UAE with about 1.5 million people, expected to be doubled in 2020 [1]. The demography of the city comprises a varied mix of nationalities and cultures. The strength of the Dubai economy is boosted mainly by the ports and national resources.

Dubai, with its hot climate, is situated 25 degrees north and 55 degrees east, within a sub-region of the northern desert belt. It is characterized by scarce rainfall and high levels for temperature, humidity and sunshine. In summer time, the weather is very hot and humid with daytime temperatures ranging from $35^{\circ} \mathrm{C}$ to $49^{\circ} \mathrm{C}$. In winter, the daytime temperatures range from $25^{\circ} \mathrm{C}$ to $35^{\circ} \mathrm{C}$, and sometimes falling to as low as $9 \circ \mathrm{C}$ at night [2].

The architectural ideologies in Dubai have moved from a traditional vernacular style to modern planning ideologies. The traditional fabric reflects the climatic condition, the cultures of the residents, and the locally available building materials. This pattern is characterized by high-density buildings with narrow shaded alleys, tall wind-towers, and courtyards. The modern approach, which was established during the second half of the 19th century, was concerned with highly specialized building techniques. This modern style is highly recognized within the new central area of Dubai. A number of enormous mega-projects have been constructed, including the world's tallest tower (Burj Khalifa). 


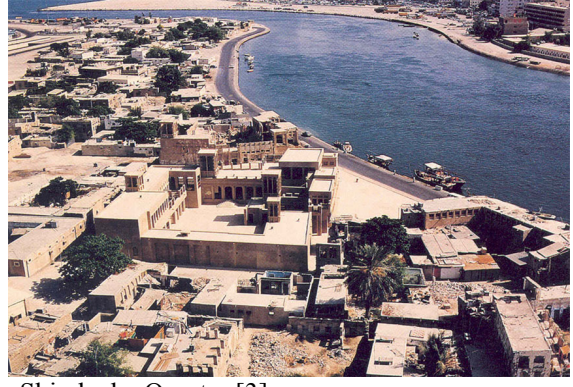

Shindagha Quarter [3]

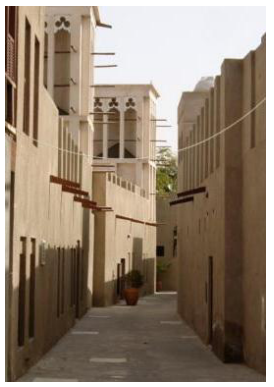

Narrow alleys, Bastikia

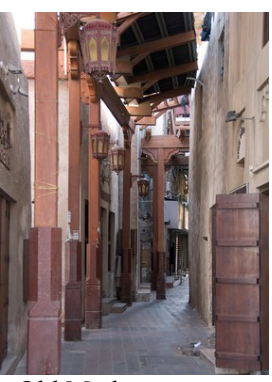

Old Market

Figure 1: $\quad$ Architectural fabric of old Dubai.
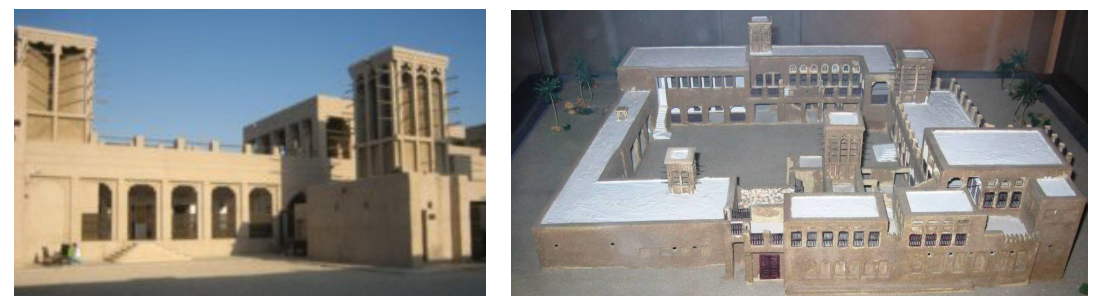

Figure 2: $\quad$ Sheik Saeed Al-Maktoum House, Shindagha, Dubai.

The architectural fabric of old Dubai provides natural cooling system to maintain a comfortable indoor temperature. Buildings tended to be very closely clustered together separated by narrow shaded alleys running from north to south to permit the prevailing winds to pass through. This fabric is well recognized in Shindagha and Bastikia Quarters (see figure 1).

Sheik Saeed Al-Maktoum House, built in 1896, is a typical example of the traditional architecture of Dubai (see figure 3). The living quarters of the house open on to the main courtyard to generate wind circulation around the rooms. Most of the rooms are provided with a shaded veranda overlooking the courtyard. Windows are mostly on the inside looking in towards the courtyard. Windows on the exterior walls are limited to narrow slits and semi-decorative openings that admit light and accelerate natural ventilation. The wooden ventilating screens (Mashrabbias) were also used to keep out the sun, and allow cool breezes. The wind-towers were the most distinctive architectural elements to trap the fresh cooling air and direct it to the indoor space below. The house was built from local high mass materials including coral stone, lime, plaster, and palm fronds. Such materials have adequate thermal storage which responds to the needs of the climate.

The trend of rapid urban development in Dubai has impacts on environmental aspects including environmental deterioration, high consumption of nonrenewable resources, and high levels of air pollution. Minimizing this impact on the natural environment and efforts to improve the ecological performance of any project are the main concerns of sustainable building development during 

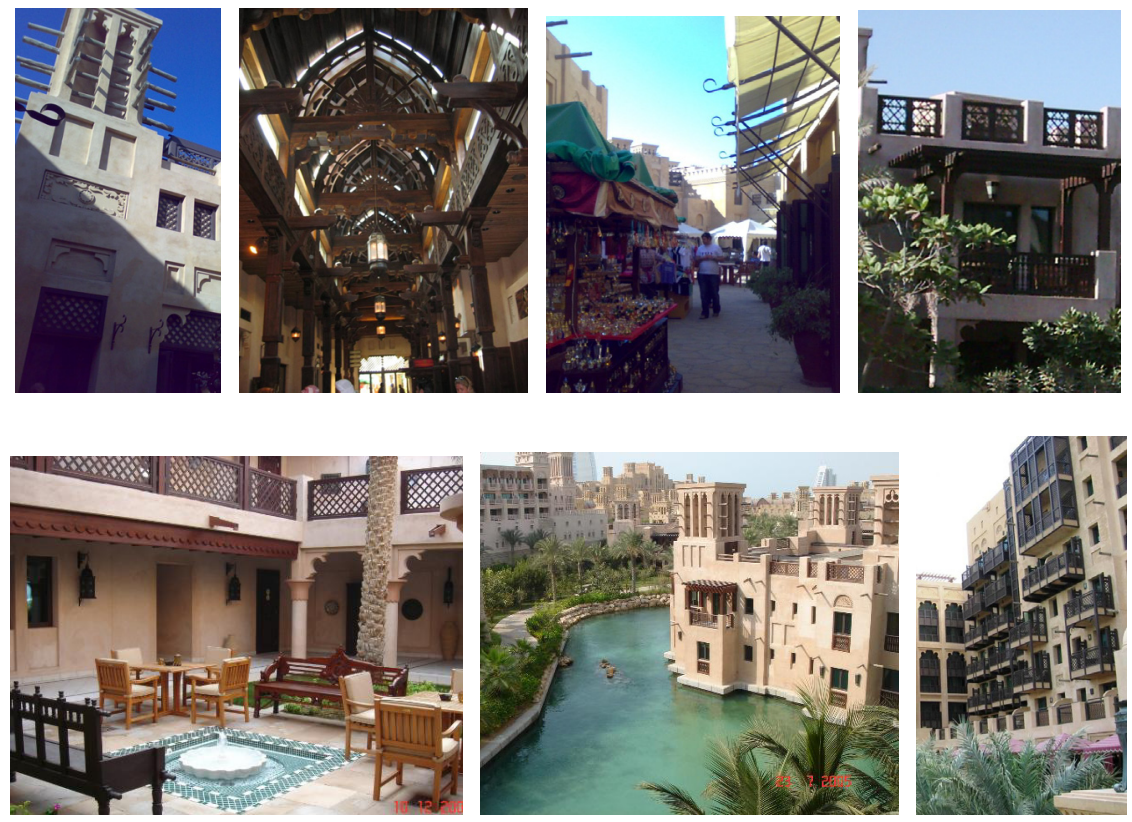

Figure 3: The use of passive strategies in a sustainable urban context, Madinat Jumeirah, Dubai (wind-towers, shading devises, courtyards, pools and canals, vegetation and landscape).

and after construction period [4]. Therefore, energy efficiency, a healthy environment, and protection of biodiversity are the key issues. It was indicated that buildings consume about $45 \%$ of total energy use; $25 \%$ of total water consumption; $70 \%$ of total electricity consumption, and about $40 \%$ of total carbon dioxide emissions [5]. These figures are even higher in Dubai and it has one of the highest per capita fossil fuel consumptions [6]. Therefore sustainable building practices, in term of energy consumption, are essential in cities like Dubai in order to adapt to sustainability.

\section{The use of passive cooling strategies in a sustainable context}

Sustainable development refers to a socio-ecological process characterized by the fulfilment of human needs while maintaining the quality of the natural environment [7]. Sustainable development could be achieved by architects, engineers, designers, town planners, and manufacturers of building products working cooperatively to produce green buildings that are designed, built, or operated in an ecological manner. Green Architecture is an approach that emphasizes the place of buildings within both local ecosystems and the global environment. Green building is the practice of increasing energy efficiency, while reducing building impact on human health and the environment. A green concept tends to focus on the use of natural materials, renewable recourses, and 
passive solar techniques [8]. Reducing energy loads is a main concern for green architecture. It is important to orient the building to take advantage of cooling breezes in a hot climate, and sunlight in a cold climate. To minimize the energy loads, passive solar design can be effective. Masonry building materials with high thermal mass are efficient. Many of these valuable passive strategies are employed in the traditional architecture of old Dubai. In Dubai's hot climate, where cooling is a primary concern, much can be done to capture natural breezes to keep buildings cool and comfortable. Courtyards, wind-towers, shading devices, thermal mass, insulations, deciduous vegetation, and green roofs and green walls can reduce energy loads for cooling.

The most important step in the passive design strategies is to develop an energy efficient building skin to minimize heat gains and catch cooling breezes. Depending on the climatic condition, passive design of the building skin might comprise the following concerns: orienting more windows to the north; incorporating adequate shading devices that prevent solar radiation; providing suitable insulation including vegetation; using high performance glazing that reduces heat gain and admit natural light. Landscape and outdoor spaces also play an important role in passive design strategies. The effective way to cool the building is to keep the heat from buildings. Specific strategies should be applied; including reflecting heat, blocking the heat, and removing built-up heat [8].

Shading, insulation, and vegetation are good strategies to block the heat and reduce the indoor temperature. Shading can reduce indoor temperatures by $10{ }^{\circ} \mathrm{C}$. Effective shading can be provided by trees and shading devices. Vegetation provides a reliable heat buffer and can save up to $20 \%$ on energy use [9]. It also minimizes the heat island effect of the building. Moreover, the plants filter outdoor pollutants and improve air quality.

Natural ventilation helps remove heat and maintains indoor temperatures. In hot-humid climates, a building designed for passive cooling would be as open as possible to ensure the maximum possible cross ventilation. East and west walls should have a minimum of windows in order to exclude the low angle sun-rays. However, north and south walls should have enough windows to allow cross ventilation. Cross ventilation can also be enhanced by irregular-shaped, spreadout buildings. The wind-tower, which is the key element of the traditional architecture of Dubai, can also be used to ensure ventilation by using the cooling potential of the available breezes. The courtyard is another passive cooling device which may improve thermal comfort conditions in enclosed building spaces.

Architects and developers, like Creative Kingdom and Mirage Mille have incorporated ecological and sustainable approaches in their designs. Various concepts and techniques have been used to develop energy-efficient buildings and cooling load avoidance. The use of natural ventilation, thermal mass, shading devises, vegetations, landscaping, and the double skin façades have been adopted.

In the last few years, various passive design techniques have been applied to new large projects in Dubai, such as Madinat Jumeirah, the largest resort established in 2004. It reflects the rich cultural heritage of Dubai and resembles 
an ancient Arabian architectural style. The project was designed and built in an ecological and resource-efficient manner. As shown in figure 3, passive design elements such as courtyards, atriums, wind-towers, shading devises, vegetations, pools and canals have been integrated to create a pleasant outdoor environment and improve indoor comfort by achieving desirable thermal conditions. These strategies minimize the need for mechanical cooling systems and then reduce energy consumption.

External insulated, dense materials covered with vegetation have been used in passive design where the plants reduce overall temperatures of the building and minimize the heat gain. This strategy utilizes plants to increase energy efficiency by functioning as a natural shading system and reducing heat gain.

\section{The use of green walls}

Green walls, also known as vertical gardens have been successfully implemented in different climatic conditions. Green wall is used as a term for both living walls and green façades. Living walls, also known as bio-walls are composed of prevegetated panels or integrated fabric systems that are fixed vertically to a structural wall or frame [10].

Green façades are made up of climbing plants that growing directly on a wall or supporting structure. The plant grows up the wall while being rooted to the ground, in intermediate planters or on the rooftops. Rigid panels and cable systems can be used to hold vines off the wall surface.

Green walls provide a wide range of positive effects for buildings, inhabitants, and the environment. There are significant benefits resulting from the use of green walls.

\subsection{Increasing energy efficiency in buildings}

Green wall technology helps buildings become more energy efficient and helps to reduce the urban heat island effect, absorb storm-water, and leads to reduced carbon emissions. It acts as a protective barrier which provides better solar protections that can reduce the effect of the external load and the cooling need [10]. Previous observations indicated that green walls reduce the heat gain, and their surface temperature is lower than an exposed wall. Based on the analysis carried out by Green over Grey firm [11], studies have shown that the external surface of a green wall is up to $10^{\circ} \mathrm{C}$ cooler than an exposed wall; therefore the U-value for the green wall is usually lower and helps to reduce cooling loads. Previous studies demonstrated that non-vegetated areas could exceed temperatures of $50^{\circ} \mathrm{C}$ in July while vegetated areas remained at $25^{\circ} \mathrm{C}$ [12]. Interior green wall technology also helps to save energy. It can reduce the temperature of the room by 3 to $7^{\circ} \mathrm{C}$, and can reduce the $\mathrm{AC}$ cost by up to $20 \%$ [11]. In winter, green wall techniques act as insulation layer by moving air between the plant and the wall and creating a buffer against the wind which reduces cool air coming in. The level of energy saving depends on many factors such as climate, building skin type, and density of plant coverage. 


\subsection{Sound insulation}

In urban environments, plants and trees have been used as barriers against urban noise pollution. Plants, soil, and the trapped layer of air can absorb, reflect or deflect sound waves. Therefore, green walls have an acoustical insulation that is far better (up to $30 \mathrm{db}$ ) than that of exposed wall [13]. The degree of sound insulation provided by the green wall depends mainly on factors that influence noise reductions including depth of the growing media, type of plants, the materials used for the structural components of the living wall system, and the layer of air between the plants and the wall. In terms of sound control, the choice of the appropriate type of green wall technique depends mainly on the site conditions, climate conditions, and the function of the inner space.

\subsection{Building surface protection}

By reducing surface temperature of a building skin, and using appropriate techniques such as waterproof living wall panels separated by a layer of air; green wall technology can protect building surfaces and extend the lifespan of the building skin. This protection comes mainly from keeping rain off the building while allow moisture to escape, reducing the expansion and contraction of building materials, and protecting walls against wind and solar radiation which might affect the building materials.

\subsection{Visual and air quality improvements}

By bringing nature to the urban environment; green wall technology has a visual impact on the architectural fabric. The use of green walls as visual attractants increases the value of the building. Moreover, green walls can help to address the lack of green space in urban environments. Plants improve human health, capture airborne pollutions, and filter harmful gases. In addition to absorbing heat and increasing thermal performance, the green wall helps to filter the air moving across it. Green wall technology contributes directly to LEED credits (Leadership in Energy and Environmental Design) since it covers issues like sustainability, energy saving, air quality, water efficiency, wellness, and acoustics.

\section{Integrating green wall techniques into the double skin façade}

Architects and building engineers believe that the use of double skin façades (DSF) can provide better natural ventilations and thermal insulation, reduce cooling loads and energy consumption, facilitate daylight, and increase noise control [14]. It can provide about $30 \%$ reduction in energy consumption [15]. In summer, DSF can reduce heat gain and cooling loads while allowing in daylight and natural ventilation. Moreover, it can reduce heat loss in winter while still capturing solar gain. As shown in figure 4, DSF introduces two primary glazing layers separated by a cavity space that provides thermal insulation. This could be 
integrated with solar control systems, light reduction systems, and ventilation systems. The construction of the DSF usually provides better solar protection that can reduce the effect of the heat gain and the cooling need. The additional layer of glazing can reduce the insulation by about $10 \%$. Further reduction could be achieved by placing shading devices in the cavity space [14].

Despite its advantages in terms of energy efficiency, the use of the DSF system is still limited in Dubai. The construction cost of the DSF is always higher than a single skin façade. However DSF may allow tradeoffs with building systems including cooling and heating systems. Previous studies indicated that the potential energy savings offered by the DSF can overcome the high construction cost and building performance can be maximized [14]. Based on a comparison analysis carried out by the author, the solar heat gain coefficient of DSF with shading devices was much lower (between 0.09 and $0.30 \mathrm{~W} / \mathrm{m} 2$ ) than that of a double glazing single skin façade (between 0.30 and $0.40 \mathrm{~W} / \mathrm{m} 2$ ). The U-value of the DSF vented with laminated shades within cavity space was between 0.9 and 1.4; while the U-value of double glazing single skin facade was between 1.1 and 1.5. It has also been indicated that DSF has an acoustical insulation that is far better than that of a conventional double glazing single-skin façade with difference of $10 \mathrm{~dB}$ [14].

To increase energy efficiency of the DSF, a vertically vegetation layer could be integrated into the cavity space of the DSF. This technique is known as vertically integrated greenhouse (VIG) [10]. The main idea of this system is that

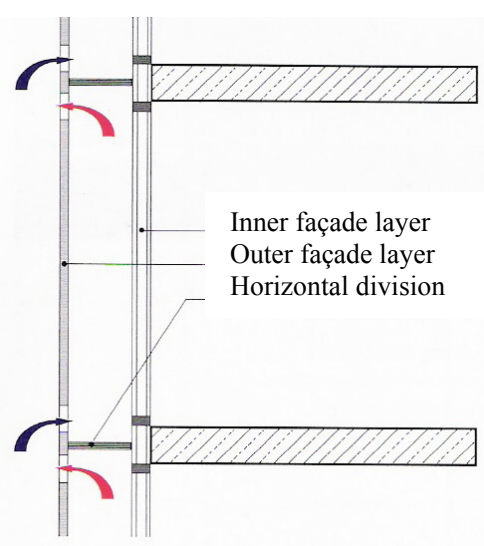

Figure 4: Section through DSF with ventilation system [16].

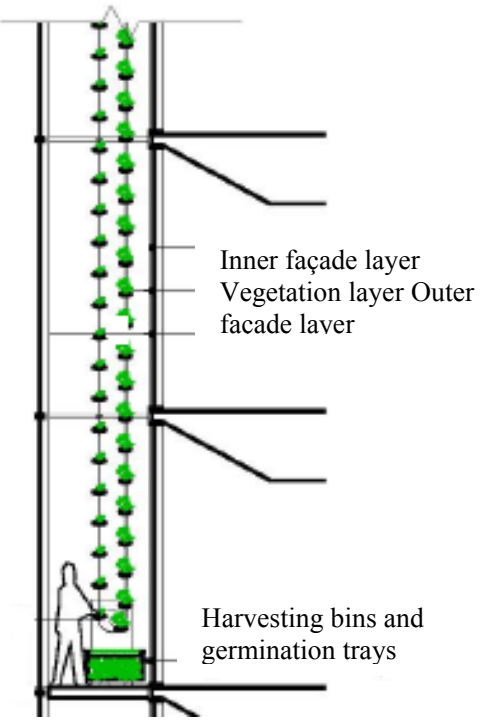

Figure 5: Vertically integrated greenhouse technique [10]. 
the installed plants can act as shading devices that help absorb heat and liberate it within the cavity (see figure 5). Moreover, installed plants increase sound insulation and improve air quality within the cavity space. Caplow et al identified the VIG concept as a highly productive, modular, and climatically responsive system for growing vegetables in a cavity space of a DSF [10]. By adding a commercial scale of vegetable production within a DSF, Caplow et al pointed out that the VIG technique helps to strengthen the economic justification of the DSF system and encourages architects and building engineers to adopt this technology.

\section{Conclusions}

Ongoing urban developments in Dubai have consequences on the environment. The trend to improve the ecological performance of buildings is the main concern of Dubai Municipality. Architects and developers have incorporated ecological and sustainable approaches in their design. Design strategies that minimize the need for mechanical cooling systems have been adapted in sustainable urban context. These strategies include proper shading, natural ventilation, thermal mass and good landscaping. Traditional architectural elements such as wind-towers, atriums and courtyards have been adapted in the new projects to enhance the stack effect and to speed the indoor air flow. Previous studies recommended that the use of dynamic double glass façades that accommodate change in the environment is highly appreciated for the fully glazed building in Dubai since it provides better solar protection that can reduce the effect of the heat gain and the cooling need.

The green wall is another environmentally friendly technique that helps buildings become more energy efficient and reduces the urban heat island effect. It provides better solar protection, sound insulation, surface protection to the building, and visual and air quality improvements. Integrating a vertical green screen into the double skin façade system (vertically integrated greenhouse) is recommended by many researches like Caplow, Nelkin, and others; since it acts as a shading device integrated within the cavity space of the DSF.

The use of green wall technology is still a new concept in Dubai, despite its great positive impacts. This technique requires extensive energy analysis and investigation in terms of thermal performance, sound control, and cooling load reduction. The study also recommends that an economic justification for adopting such technology is required.

\section{References}

[1] The United Arab Emirates Yearbook 2006.

[2] www.datadubai.com/technical-info.

[3] Kay, S and Zandi, D., Architectural Heritage of the Gulf, Philip Morris, 1995.

[4] Botta, M., Towards Sustainable Renovation Three Research Projects. KTH, Stockholm, 2005. 
[5] Walters, L. et al, Miracle or Mirage: Is Development Sustainable in the United Arab Emirates? Middle East Review of International Affair, vol. 10, no. 3, 2006.

[6] Abou Alnaga, M. and Y. El-Sheshtawy, Environmental Sustainability Assessment of Buildings in Hot Climates: The Case of the UAE, Al-Ain, UAE, 2001.

[7] Rees, W. 1998, "Understanding Sustainable Development", Sustainable Development and Future Cities, Hamm, P. and P. Muttagi (eds), Intermediate Technology Publications, London.

[8] www.empowementzon.com

[9] Roehr, D. and J. Laurenz, Green Surfaces in the City Context, Proceeding of The Ecocity World Summit, San Francesco, USA, 2008.

[10] Caplow, T. et al., Vertically Integrated Greenhouse: Realizing the Ecological Benefits of Urban Food Production, Proceeding of The Ecocity World Summit, San Francesco, USA, 2008.

[11] Green over Grey - Living Walls and Design, www.greenovergrey.com

[12] Luvall, J., and H. Holbo, Measurements of short-term thermal responses of coniferous forest canopies using thermal scanner data. Remote Sensing of Environment, vol. 27:1-10, 1989.

[13] www.greenroofs.org/index.php/about-green-roofs/green-roof-benefits

[14] Haggag, M., Integrating Intelligent Glass Facades into Sustainable Buildings, Proceeding of the 2nd International Conference on Energy and Sustainability, Bologna, Italy. 2009.

[15] Oesterle et al, Double-Skin Facades, Prestel Verlag, London, 2001.

[16] Glicksman, L. et al, Double Skin, Airflow Façades. Proceeding of the International Conference on Building Envelope Systems and Technologies, Ottawa: Canada, Vol. 1, pp. 203-207, 2001. 